FRENCH BUSINESS CORRESPONDENCE COURSE 


\section{DISCLAIMER}

The company names and addresses which appear in this Course are realistic but not, as far as is known, real. Similarly the letters, the situations on which they are based and their senders and recipients, are all fictitious.

There is one exception to the above. The name IBM has been included because it is indispensable in the context of office technology and business information systems. IBM is the registered trademark of the International Business Machines Corporation. 


\title{
FRENCH BUSINESS CORRESPONDENCE COURSE
}

\author{
Derrik Ferney \\ B.A., M.A., M.Sc., P.G.C.E. \\ School of Languages and European Studies \\ The Polytechnic, Wolverhampton
}

MACMILLAN MULTILINGUAL BUSINESS SERIES

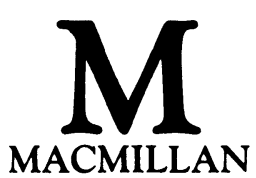


(C) Derrik Ferney 1989

All rights reserved. No reproduction, copy or transmission of this publication may be made without written permission.

No paragraph of this publication may be reproduced, copied or transmitted save with written permission or in accordance with the provisions of the Copyright Act 1956 (as amended), or under the terms of any licence permitting limited copying issued by the Copyright Licensing Agency, 33-34 Alfred Place, London WC1E 7DP.

Any person who does any unauthorised act in relation to this publication may be liable to criminal prosecution and civil claims for damages.

First published 1989

Published by MACMILLAN EDUCATION LTD

Houndmills, Basingstoke, Hampshire RG21 2XS

and London

Companies and representatives

throughout the world

Typeset by Gecko Limited, Bicester, Oxon

British Library Cataloguing in Publication Data

Ferney, Derrik

French business correspondence. -

(Macmillan multilingual business series)

1. International business correspondence in

French - Manuals

I. Title

$808^{\prime} .066651041$

ISBN 978-0-333-49433-2 ISBN 978-1-349-10914-2 (eBook)

DOI 10.1007/978-1-349-10914-2 


\section{CONTENTS}

Acknowledgements

About this Course

vii

Introduction

viii

How to use this Course

Summary of Course Aims

1. Enquiries and Offers

2. Orders

3. Delivery, Transport, Customs

4. Invoices, Payments and Reminders

5. Complaints

6. Agencies

7. References

8. Job Applications and Advertisements

9. Change of Address etc.

10. Travel and Hotel Reservations

11. Property: Sales and Rentals

12. Financial Reports

13. Bank and Post Office

14. Insurance

15. Office Terminology and Technology

Appendix: Example Curricula Vitae and Testimonals 


\section{ACKNOWLEDGEMENTS}

The Author and the Publishers are grateful to Renée Kendall-Tobias and Stuart Williams for the contribution they made to developing the letters in this book. The Author would also like to thank SEGI Services (Gravure-Imprimerie) of Grenoble for the many examples of letter-heads which were made available to him. 


\section{ABOUT THIS COURSE}

The principle on which the Multilingual Business Correspondence Course is based is a simple one. Analysis of any significant corpus of business correspondence reveals that a number of relatively unchanging, context-independent linguistic formulae, in conjunction with a number of contextdependent terms and expressions, account for a significant proportion of the content of business letters.

These formulae, terms and expressions can be regarded as the building blocks of written communications between firms. Letter-writing in the foreign language becomes a considerably easier task if students have access to these building blocks and, through regular practice, are able to assimilate them into their active vocabulary.

The Multilingual Business Handbook, with which this Course is intended to be used, gives students easy access to some 1800 of these building blocks in each of 5 languages.

The Multilingual Business Correspondence Course, of which this French Course is a part, provides students with the practice required to assimilate them.

This is not of course to say that a knowledge of fixed formulae, terms and expressions is in itself sufficient to account for the creativity inherent in writing business letters in a foreign language, merely that it can provide a useful starting point. The terms and expressions which are contained in the Multilingual Business Handbook and used in this Course are no substitute for competence in the foreign language, but they can both help students develop that competence and provide accomplished linguists with access to the business language with which they may be unfamiliar. 


\section{INTRODUCTION}

This course is intended for Intermediate or Advanced level students of foreign languages for business purposes. In designing the course two major considerations have been borne in mind: that it should be a teaching course and that it should be compatible with modern approaches to language teaching.

\section{A Teaching Course}

Regrettably, students often come to perceive letter-writing in the foreign language as an arduous dictionary-based task reminiscent of unseen prose translation. This Course sets out to counter that perception by creating a graded, supportive and realistic learning environment which helps students acquire the translation and composition skills required to deal with business correspondence. This is achieved in the following way:

- Letters are graded in order of increasing linguistic and situational difficulty. Students learn how to compose complex business letters by first dealing with simpler ones.

- The teaching/learning process is supported at every stage by the Multilingual Business Handbook. Most of the letters are accompanied by a translation aid in the form of a 'skeleton' of key letters and numbers (A1, B7, R77 etc.) which act as pointers to terms and expressions contained in the Multilingual Business Handbook. The provision of 'skeletons' dispenses with the need for lengthy dictionary searches and permits students to deal with complex correspondence relatively quickly.

- Every section contains two scenarios of three letters each. These letters simulate a continuing exchange about a specific issue, for example a disputed insurance claim or damage to goods in transit. The realism implicit in this simulation means that in the classroom, as in real business practice, one can frequently derive key terms, expressions and structures from previous exchanges within the same context, and use them to aid the production of the new letter. This Course is designed to model the association of incoming with outgoing correspondence and to do so in exchanges of increasing linguistic and situational difficulty.

\section{Modern Approaches to Language Teaching}

Modern approaches to teaching languages for business purposes tend to assess student learning by means of integrated exercises or assignments. These consist of simulations of business activities involving case studies, role playing and the deployment of a range of listening, speaking, reading and writing skills to accomplish a set of realistic tasks. The translating and writing of business letters normally feature quite prominently in the assignment-based approach, not only because of the realism inherent in such tasks but also because they act as an appropriate vehicle for practising writing in the foreign language. This Course aims precisely to provide, within the context of the assignment-based approach, the regularity of practice and the gradual development of skills necessary for successful letter writing in the foreign language.

Modern approaches to learning business languages also tend to stress the importance of autonomous learning, information retrieval and the use of appropriate materials and technologies to support these activities. This course is uniquely placed in this respect, since it is intended to be used with the Multilingual Business Handbook. 
This is a definitive guide to commercial letter writing in English, French, German, Spanish and Italian and is currently published in Britain, France, Germany, Italy, Holland, Spain and the United States. It contains approximately 1800 expressions and phrases in each language, divided into sections such as Enquiries and Offers, Orders, etc. Within each section, every expression has a key letter and number (A36, B39 etc.) which corresponds exactly to the appropriate expression in each of the other languages.

Most of the letters in the Multilingual Business Correspondence Course are accompanied by a 'skeleton' of the form (A1, A7, B26, C90 etc.) which enables the student to retrieve from the Handbook key phrases which will be of help in the translation of the associated letter.

\section{An Integrated Package}

In combination with the Multilingual Business Handbook and the LinguaWrite Computer Database, the Multilingual Business Correspondence Course provides an integrated and pedagogically sound learning package which is compatible with modern language teaching practice. It can be used on a stand-alone basis or as a complement to the assignment-based approach to enable students to learn about business correspondence by translating and writing letters of increasing complexity.

Furthermore the database provides students with the opportunity of using information technology as an integral part of the learning process, and can be used with the computer's word-processing facility to enable letters of business quality to be produced. 


\section{HOW TO USE THIS COURSE}

\section{The Course Structure}

The course is divided into 15 sections, each of which is based on one or more sections of the Multilingual Business Handbook. The sections are further divided into two sub-sections, A and B, with three letters in each. Each letter is identified according to the sub-section and section to which it belongs. For example, Section 1 of the course contains letters 1A1, 1A2, 1A3, 1B1, 1B2 and 1B3. Section 2 contains letters $2 \mathrm{~A} 1,2 \mathrm{~A} 2,2 \mathrm{~A} 3,2 \mathrm{~B} 1,2 \mathrm{~B} 2$ and $2 \mathrm{~B} 3$, etc.

\section{Different Paths through the Course}

Those letters whose identifier contains the character $\mathrm{A}$ are primarily intended for use by students who have already completed a course of study in French, and who are continuing with the language in preparation for A/S level or the intermediate awards of bodies such as BTEC, RSA, Institute of Linguists or LCCI. Those letters whose identifier contains the character B are primarily intended for use by higher diploma or degree level students of French for business purposes, including those preparing for higher level RSA or Institute of Linguists examinations. The Course thus provides for different start-levels according to the students' prior experience of the language.

Teachers wishing to provide a course aimed primarily at post-GCSE (or equivalent) students can work on the simpler sub-section A of each section, whilst post 'A' Level (or equivalent) students can work on the corresponding but more complex sub-section B. Conversely teachers may decide to ignore this distinction and simply work through the course section by section, selecting letters from both sub-sections as they see fit.

Different paths can thus be followed through the course according to student needs.

\section{Section Layout}

Each section of the Course deals with a different type of letter and is divided into two sub-sections comprising three letters each. The three letters are associated by situation and context, simulating ongoing correspondence between foreign and British companies. Letter 1 of each sub-section is written in the foreign language for translation into the student's mother tongue. A 'skeleton' of key letters and numbers taken from the Multilingual Business Handbook points the student towards the key phrases contained in the letter and acts as a translation aid. Each sub-section has been devised so that many of the terms and expressions learned by the student in the course of translating letter 1 into his/her mother tongue can subsequently be used to translate letter 2 into the target language. Again a 'skeleton' is provided for this translation task. Letter 3 then provides the opportunity for further practice, continuing the exchange commenced by letters 1 and 2 but allowing the student freer expression, not only because of its guided composition format, but also because it is not accompanied by a 'skeleton' derived from the Handbook. Typically, then, the teacher might work with students on letters 1 and 2 in class and set the associated letter 3 as a homework exercise.

\section{Progress through the Sections}

The letters contained in the sections increase in complexity as students progress through the Course. This increase in complexity manifests itself in a number of ways. Firstly, the situations dealt with in 
the sections become progressively more elaborate, with a concomitant increase in letter length. Secondly, the language structures and terminology used increase in difficulty and specificity, and the role of tone is developed. Thirdly, the proportion of a given letter accounted for by the terms and expressions whose key letters and numbers are found in the associated skeleton diminishes as the Course proceeds. This is particularly true of the later letters in the foreign language, which are designed to expose students to a variety of terms, expressions and language structures not contained in the Multilingual Business Handbook. These are then reworked in the reply, the composition of which is aided by the usual skeleton of key letters and numbers, which point students to helpful terms and expressions in the Multilingual Business Handbook. Here again, in the later sections students will be expected to modify these terms and expressions to suit specific situations of use. The need to effect tense shifts, change syntax and substitute vocabulary means that students gradually come to use the building blocks as a springboard for creative writing in the foreign language.

\section{Letter Layout}

Letter layout is a moot point. Various sets of 'rules' have been suggested, but in reality the practices adopted by firms often defy these supposed conventions. For example, some firms clearly regard letter-heads and letter layout as important and distinctive features of house style, and consciously choose to break with what they regard as conventional layout. Extrinsic factors such as the type of envelope a firm normally uses can also influence letter layout, with window envelopes, for example, usually requiring the recipient's address to be positioned adjacent to the left-hand margin of the letter in Britain and the right-hand margin of the letter in France. The various letter layouts used in this Course reflect current business practice and are intended to cover the most important aspects of format in as clear a manner as possible. They should not, however, be regarded as prescriptive and students will, in any case, quickly discover the particular practices of their employer upon starting work or commencing a training period.

Students preparing for public examinations in which letter layout is a component should of course follow the rules for layout prescribed by the Examination Board in question. 


\section{SUMMARY OF COURSE AIMS}

The Multilingual Business Correspondence Course aims to provide:

1. A structured teaching/learning package as opposed to a corpus of business correspondence.

2. Materials which can be equally well used on a stand-alone basis or as part of an assignment-based course.

3. Maximum opportunity for autonomous learning on the part of the student, through its integration with the Multilingual Business Handbook.

4. The opportunity for students to use information technology as a regular part of their learning activities, through its integration with the LinguaWrite Computer Database.

5. Different paths through the course for students of different language levels.

6. A realistic learning environment in which business letters are associated by function and context in a genuinely communicative manner.

7. A pedagogically sound learning environment in which letter reception precedes letter production.

8. An enjoyable learning experience for students, by focusing on what they can do as opposed to what they cannot. 